\title{
HIV:
}

\section{low prevalence is no excuse for not testing}

\section{HIV IN UK PRIMARY CARE}

There are currently an estimated 86500 individuals living with HIV infection in the UK, one-quarter of whom are unaware of their infection. ${ }^{1}$ Of the 6630 adults newly diagnosed in 2009, $52 \%$ had a CD4 count less than $350 \times 10^{6} / \mathrm{L}$ at the time of diagnosis, the recommended threshold at which antiretroviral therapy should be commenced. ${ }^{1}$ Thirty per cent were diagnosed with a CD4 count less than $200 \times 10^{6} / \mathrm{L}$, which is indicative of severe immune deficiency and associated with a significantly higher risk of death in the first 3 months.

Earlier diagnosis allows more timely initiation of therapy and is associated with a higher estimated life expectancy than for individuals started on treatment in late disease. Approximately one-quarter of all deaths in HIV-positive people are attributable to late diagnosis. ${ }^{2}$ Furthermore, earlier diagnosis has potential benefits to the wider public health. Knowledge of HIV infection is associated with behaviour change to reduce the risk of onward transmission. ${ }^{3}$ In addition, effective antiretroviral therapy substantially reduces the infectiousness of the HIV-positive individual, significantly reducing the likelihood of onward transmission to a potentially negligible level. ${ }^{4}$ The Health Protection Agency recently estimated that the prevention of one new HIV infection saves the public purse between $£ 280000$ and $£ 360000$ in direct lifetime healthcare costs. ${ }^{5}$

The public health challenge is to reduce the number of undiagnosed individuals, and to diagnose people living with HIV infection earlier. There is widespread agreement on the need for greater and wider testing for HIV infection outside the traditional setting in sexual health clinics, including testing in primary care and community settings. Since 2001, increasing HIV testing in primary care has been part of the National Strategy for Sexual Health and HIV in England. ${ }^{6}$
GPs in both high and low prevalence areas have an important role to play in meeting this challenge. In a recent study of patients newly diagnosed with HIV, the majority had been seen for care in general practice in the previous 12 months, suggesting opportunities for earlier diagnosis may have been missed. ${ }^{7}$ Late diagnosis is higher in individuals over the age of 50 years, a group more likely to have attended primary care. ${ }^{1}$

\section{APPROACHES TO TESTING}

What testing strategies are appropriate for general practice, and are these likely to be different in areas of low or high prevalence of HIV infection in the local population? The 2008 UK National HIV Guidelines for HIV Testing advocate different testing strategies for areas of different HIV prevalence. ${ }^{8}$

In areas where prevalence of diagnosed HIV infection exceeds 2 in 1000, universal screening for all newly registered adult patients is recommended (Table 1, part A). Non-UK data suggest screening at this threshold is cost-effective, and UK costanalysis is currently being undertaken. ${ }^{9}$

For the majority of the UK population, in whom prevalence is less than 2 in 1000, a targeted approach is advocated. Testing is recommended for individuals from populations with known high HIV prevalence or that have a higher risk of exposure (Table 1, part B), and for individuals who present with conditions where HIV infection may form part of the differential diagnosis (Table 1, part C). These indicator diseases are surprisingly common in general practice.

\section{'NORMALISING' THE HIV TEST}

Current rates of HIV testing in primary care are low. There are large variations between practices, with some promoting HIV testing and others not testing at all. ${ }^{10}$

Recent data suggest patients find the routine offer of an HIV test in primary care

\section{Table 1. Guidelines for HIV testing in general practice.}

Areas were diagnosed HIV prevalence $>2$ in $1000^{\mathrm{b}}$

(A) HIV test offered to all adult patients newly registered to general practice

\begin{tabular}{ll} 
All general practices, regardless of local HIV prevalence \\
$\begin{array}{ll}\text { (B) HIV testing } & \text { (C) HIV test offered to patients } \\
\text { routinely } & \text { presenting with indicator } \\
\text { offered to: } & \text { diseases including: }\end{array}$ \\
\hline $\begin{array}{ll}\text { 1. Injecting drug users } \\
\text { 2. People from countries of } \\
\text { high HIV prevalence }(>1 \%)\end{array}$ & $\begin{array}{l}\text { 1. Bacterial pneumonia } \\
\text { 2. Peripheral neuropathy }\end{array}$ \\
$\begin{array}{ll}\text { 3. Men who have sex with men } & \text { dermatitis or psoriasis } \\
\text { 4. Sexual partners of HIV } & \text { 4. Multidermatomal/recurrent } \\
\text { positive individuals } & \text { herpes zoster } \\
& \text { 5. Oral candidiasis } \\
& \text { 6. Chronic diarrhoea of } \\
& \text { unknown cause } \\
\text { 7. Weight loss of unknown cause } & \text { 8. Lymphadenopathy of } \\
\text { unknown cause } \\
\text { 9. Sexually transmitted } \\
\text { infections (other than HIV) } \\
\text { 10. Pyrexia of unknown origin }\end{array}$
\end{tabular}

${ }^{2}$ Adapted from UK National Guidelines for HIV Testing 2008. ${ }^{8}$ biagnosed HIV prevalence by primary care trust is available from the Health Protection Agency survey of prevalent HIV diagnoses (http://www.hpa.org.uk/web/HPAweb\&HPAwebStandard//HPAweb_C/1201767906579). 'Ten indicator diseases thought to be most relevant to general practice are listed. A full list is in the UK National Guidelines for HIV testing 2008. ${ }^{8}$ 
acceptable, with most proceeding to test. ${ }^{9}$ Reasons for patients not testing include a recent negative test or a belief they were not at risk. Extensive pretest counselling is not considered necessary for most people. The essential elements of pretest discussion are to explain the benefits of testing for the individual and how the result will be given, which is no different from most other medical tests. ${ }^{8}$ Written consent is usually unnecessary which is consistent with General Medical Council guidance on consent. ${ }^{1}$

HIV infection is still an uncommon diagnosis for most GPs and this may contribute to low testing rates. However, an important role for GPs is in diagnosis, including consideration of uncommon conditions: combined prevalence of 'rare' diseases in general practice is approximately $6-8 \% .^{12}$

As patients with HIV get older, GPs are likely to assume a greater role in their routine care, managing unrelated pathology as well as the complications of HIV. ${ }^{13,14}$ Increasing testing now may help to develop the skills and confidence to achieve this.

Early diagnosis of HIV is no different from that of other chronic diseases in that it substantially improves treatment outcome. We therefore argue that missing HIV infection in primary care should be considered no differently to failure in diagnosis of any other chronic medical condition or even that of cancer. A large proportion of individuals who are HIVpositive remain undiagnosed. HIV testing is simple to perform, does not require lengthy pretest discussion, and is acceptable to the majority of patients.

We would urge GPs to increase HIV testing, and argue that this is important in both low and high HIV prevalent areas in the UK.

\section{Paul Arkell,}

Academic FY1 Doctor, West Midlands Deanery.

\section{Ewen Stewart,}

GP, Rose Garden Medical Centre, Leith and Chair of the Sex Drugs and HIV Group, Royal College of General Practitioners.

\section{lan Williams,}

Senior Lecturer at University College London and Chair of the British HIV Association.

\section{Provenance}

Commissioned, not externally peer reviewed.

\section{REFERENCES}

1. Health Protection Agency. HIV in the United Kingdom 2010 Report.

http://www.hpa.org.uk/Publications/InfectiousDisease /HIVAndSTIs/1011HIVUK2010Report/ (accessed 3 Mar 2011).

2. Lucas SB, Curtis H, Johnson MA. National review of deaths among HIV-infected adults. Clin Med 2008; 8(3): 250-252.

3. Pinkerton SD, Holtgrave DR, Galletly CL. Infections prevented by increasing HIV serostatus awareness in the United States, 2001 to 2004. J Acquir Immune Defic Syndr 2008; 47(3): 354-357.

4. Attia S, Egger M, Müller M, et al. Sexual transmission of HIV according to viral load and antiretroviral therapy: systematic review and meta-analysis. AIDS 2009; 23(11): 1397-1404.

5. Health Protection Agency. HIV in the United Kingdom 2009 report.

http://www.hpa.org.uk/Publications/InfectiousDiseases /HIVAndSTIs/0911HIVUK2009Report/ (accessed 3 Mar 2011)

6. Department of Health. Better prevention, better services, better sexual health. The national strategy for sexual health and HIV. London: Department of Health, 2001. http://www.medfash.org.uk/publications/documents/n at_shs-2001.pdf (accessed 3 Mar 2011).

7. Burns FM, Johnson AM, Nazroo J, et al. Missed

opportunities for earlier HIV diagnosis within primary and secondary healthcare settings in the UK. AIDS 2008; 22(1): 115-122.

8. British HIV Association, British Association of Sexual Health and HIV, British Infection Society. UK national guidelines for HIV testing 2008. London: BHIVA, 2008. http://www.bhiva.org/documents/Guidelines/Testing/G linesHIVTest08.pdf (accessed 3 Mar 2011).

9. Health Protection Agency. Time to test for HIV: Expanded healthcare and community HIV testing in England.

http://www.hpa.org.uk/Publications/InfectiousDisease /HIVAndSTIs/1011TimetotestHIVtesting/ (accessed 3 Mar 2011).

10. Sadler K, Low N, Mercer C, et al. Testing for sexually transmitted infections in general practice: cross sectional study. BMC Public Health 2010; 10: 667.

11. General Medical Council. Consent: patients and doctors making decisions together. http://www.gmcuk.org/static/documents/content/Consent_0510.pdf (accessed 3 Mar 2011).

12. European Organisation for Rare Diseases. Rare diseases understanding this public health priority. Paris: EURORDIS; 2005.

http://www.eurordis.org/IMG/pdf/princeps_document -EN.pdf (accessed 3 Mar 2011).

13. Defty H, Smith H, Kennedy M, et al. GPs' perceived barriers to their involvement in caring for patients with HIV: a questionnaire-based study. Br J Gen Pract 2010; 60(574): 348-351.

14. Sacks J, Goodburn E. 'Not rocket science': managing STIs in the integrated care setting of UK general practice. Br J Gen Pract 2009; 59(569): 948-950.

DOI: 10.3399/bjgp11X567009

\section{ADDRESS FOR CORRESPONDENCE}

\section{Paul Arkell}

(Courtesy of D. Jackson)

Postgraduate Office, Clinical Education

Centre, University Hospital North

Staffordshire, Stoke-on-Trent, ST4 6QG.

E-mail: paularkell@doctors.org.uk 